\title{
A Novel Clamp-Mode Coupled-Inductor Boost Converter with High Step-Up Voltage Gain
}

\author{
Kaweewat Tattiwong* and Chanin Bunlaksananusorn ${ }^{\dagger}$
}

\begin{abstract}
In this paper, a new coupled inductor DC-DC converter with a high step-up voltage gain is proposed. It is developed from a clamp-mode coupled-inductor boost converter by incorporating an additional capacitor and diode. The proposed converter is able to achieve the higher voltage gain, while still retaining the switch voltage clamp property of its predecessor. In the paper, operation and analysis of the proposed converter are described. Experimental results from a prototype converter are presented to verify the validity of the analysis. The prototype circuit attains the highest efficiency of $92.8 \%$.
\end{abstract}

Keywords: High step-up gain DC-DC converters, Clamp-mode coupled-inductor boost converter, DC-DC converter analysis

\section{Introduction}

Nowadays, a DC-DC converter with a high step-up voltage gain has become an essential component in modern power electronics applications [1-3]. For example, in automobile head lamps, a DC -DC converter is required to increase a battery voltage of $12 \mathrm{~V}$ into $100 \mathrm{~V}$ to supply a high-frequency inverter that drives a High Intensity Discharge (HID) lamp. In telecommunication centers, a power supply for a server computer is capable of working with dual input sources from an $\mathrm{AC}$ main and a $48 \mathrm{~V}$ backup battery. The battery voltage is fed to the power supply via a front-end DC-DC converter. When the main power outage occurs, the front-end converter provides a backup power by boosting the battery voltage into a $380 \mathrm{~V}$ bus voltage to continually supply downstream converters in the power supply system. Therefore, the server computer can continue to function despite the main power failure. Lastly, in power generation by solar PV or fuel cells, a DCDC converter is often used to boost a small DC voltage generated from these renewable sources to a suitable value for a gird connected inverter. The DC-DC converters used in the above applications have the following common characteristics: (1) high step-up voltage gain, (2) high efficiency, and (3) no electrical isolation between input and output. The conventional power electronic circuit used for stepping up a DC voltage is a boost converter. In theory, the boost converter can produce a high voltage gain when operated at an extreme duty cycle (i.e. the duty cycle approaching one). However, in practice, due to component non-idealities, such as the inductor resistance, the diode

$\dagger$ Corresponding Author: Faculty of Engineering, King Mongkut's Institute of Technology Ladkrabang, Bangkok 10520, Thailand. (chanin.bu@kmitl.ac.th)

* Faculty of Engineering, King Mongkut's Institute of Technology Ladkrabang, Bangkok 10520, Thailand. (56601455@kmitl.ac.th)

Received: July 25, 2016; Accepted: December 15, 2016 forward voltage drop, the switch on-state resistance etc., losses and voltage drops in the circuit increase with the increasing duty cycle. As a result, the efficiency and voltage gain of the boost converter are degraded, when the duty cycle is large $[4,5]$. Besides, operating the boost converter at the extreme duty cycle means its rectifier diode has less time to conduct. The diode current thus becomes a narrow pulse with high current amplitude, which is responsible for a severe reversed recovery loss and EMI problems.

A simple solution to increase the voltage gain without extending the duty cycle is to use a cascade boost converter, in which two or more boost converters are connected in series [6]. This method, however, requires more power switches, i.e. one power switch per one boost stage, and suffers from low overall efficiency when a number of the boost stage is increased. In [7-10], an N-stage cascade boost converter with one active switch is proposed. It uses only one power switch and has the same voltage gain as the $\mathrm{N}$ boost converters connected in series. The main drawbacks of this topology, nonetheless, are high current and voltage stresses associated with the power switch, and the low efficiency due to multi-stage power processing. High gain DC-DC converters based on a coupled inductor [11-21] can overcome the efficiency and voltage stress problems of the aforementioned cascade converter. The coupled inductor converters achieve the high voltage gain by utilizing the coupled inductor's turn ratio, instead of cascading multiple boost stages, hence leading to the improved efficiency. Moreover, unlike the cascade converter which subjects its power switch to the output voltage during turn-off, a power switch in the coupled inductor converters operates with less voltage stress as the turn-off voltage is usually considerably less than the output voltage. In this respect, the advantage of the coupled inductor converters over the cascade converter becomes 
distinct when the output voltage is high. Among many coupled inductor converters, a clamp-mode coupledinductor boost converter [12] is a very attractive topology. Its salient features include: (1) a simple circuit structure using only one power switch, (2) high voltage gain controlled by the coupled inductor's turn ratio, (3) a switch voltage clamp reducing the device voltage stress, and (4) high efficiency.

This paper proposes a new coupled inductor DC-DC converter with a high step-up voltage gain. It is developed from a clamp-mode coupled-inductor boost converter by incorporating an additional capacitor and diode. The proposed converter is able to achieve the higher voltage gain, while still retaining the switch voltage clamp property of its predecessor. Furthermore, the laboratory prototype demonstrates that the proposed converter operates with high efficiency. The reminder of this paper is organized as follows. Section 2 explains the evolution of the proposed converter. Section 3 describes the converter operation and analysis. Section 4 further simplifies the converter analysis via waveform approximation to facilitate the derivation of important current equations. Section 5 presents experimental results from the prototype converter. The results are used to verify validity of the analysis. Finally, conclusions are drawn in Section 6.

\section{Evolution of Proposed Converter}

The clamp-mode coupled-inductor boost converter is shown in Fig. 1(a). The coupled inductor has two windings, with $N_{l}$ and $N_{2}$ being a number of turns of primary and secondary windings. $D_{l}$ and $C_{l}$ constitute a clamp circuit. When $S W$ is turned on, energy is stored in the coupled inductor, and the output capacitor $C_{3}$ is discharged to supply the load current. When $S W$ is turned off, the stored energy is released to charge the output capacitor. Meanwhile, $D_{I}$ is turned on and the switch voltage is clamped to $V_{C I}$. During this turn-off interval, the output voltage is given by the sum of the input voltage and the induced voltages on the primary and secondary windings, which are additive. It is shown in $[11,12]$ that the voltage gain and clamp voltage of the clamp-mode coupledinductor boost converter are given by

$$
\begin{gathered}
\frac{V_{o}}{V_{i n}}=\frac{1+n D}{1-D}, \\
V_{C 1}=\frac{V_{i n}}{1-D},
\end{gathered}
$$

where $n=N_{2} / N_{l}$ is the coupled inductor's turn ratio and $D$ is a duty cycle of $S W$. As seen in (1) and (2), the switch clamp voltage, $V_{C l}$, is lower than the output voltage, resulting in the low voltage stress on SW. Consequently, the switch can be implemented by an inexpensive lowvoltage rated power MOSFET.

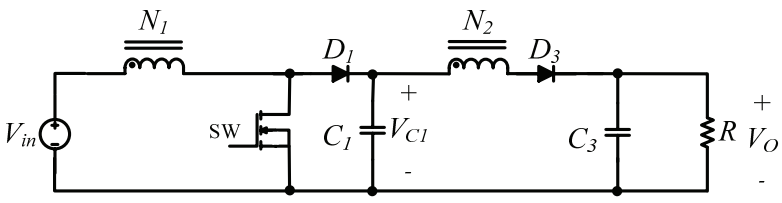

(a)

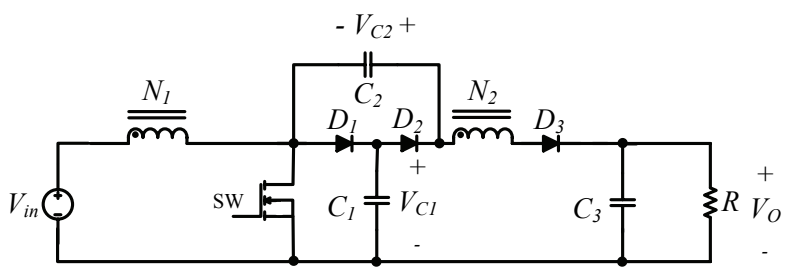

(b)

Fig. 1. (a) Clamp-mode coupled-inductor boost converter, and (b) the proposed converter

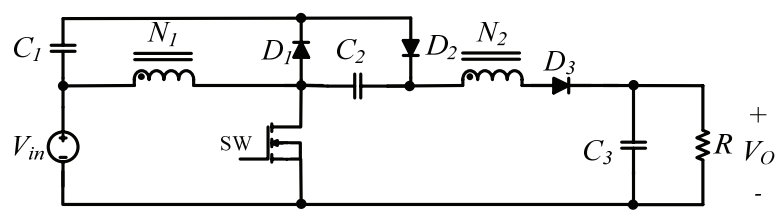

(a)

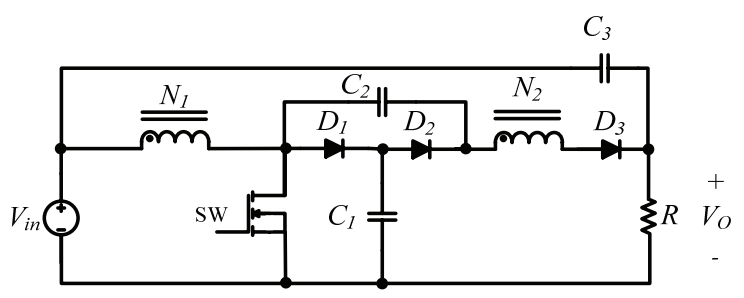

(b)

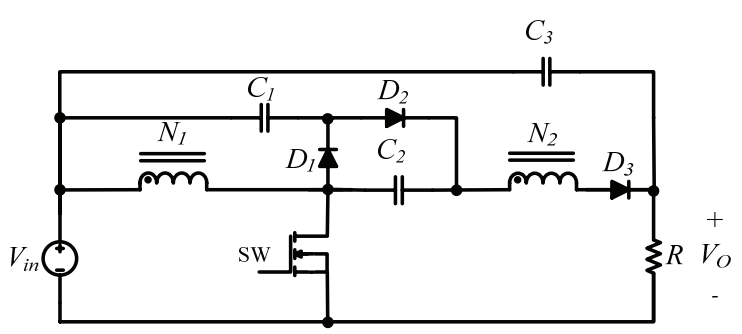

(c)

Fig. 2. Circuit variations of the proposed converter

The proposed converter in Fig. 1(b) is derived from the clamp-mode boost converter in Fig. 1(a) by the addition of $C_{2}-D_{2}$. Similar to its predecessor, the proposed converter stores energy in the coupled inductor during $S W$ turn-on. When $S W$ is turned off, the stored energy is released to charge the output capacitor and the switch voltage is clamped to $V_{C l}$ via $D_{I}$. During this turn-off interval, the output voltage is given by the sum of the input voltage, the induced voltages on the primary and secondary windings which are additive, and the voltage across $C_{2}$ (i.e. $V_{C 2}$ ). The additional voltage provided by $C_{2}$ helps increase the 
output voltage of the proposed converter, allowing it to achieve a higher voltage gain than the clamp-mode boost converter.

Other circuit variations of the proposed converter are depicted in Fig. 2. They are obtained by repositioning $C_{1^{-}}$ $D_{1}, C_{2}-D_{2}$, and $C_{3}$ of the circuit in Fig. 1(b). In these variant circuits, $C_{1}-D_{1}$ serves to clamp the switch voltage and $C_{2}-D_{2}$ serves to enhance the voltage gain. All the converters in Fig. 2 have the same voltage gain and switch clamp voltage as the proposed converter in Fig. 1(b). Operation and analysis of the proposed converter are described next.

\section{Operation and Analysis of Proposed Converter}

The converter operation is described and analyzed using the circuit shown in Fig. 3(a), where $L_{m}$ is a magnetizing inductance of the coupled inductor. The primary and secondary voltages are related by: $v_{2}=n v_{l}$, where $n=$ $N_{2} / N_{I}$ is the coupled inductor's turn ratio. The primary and secondary currents are related by: $i_{1}=n i_{2}$. To simplify the description and analysis, a leakage inductance of the coupled inductor is neglected. The input voltage, $V_{i n}$, is constant. All the capacitor $C_{1}, C_{2}$ and $C_{3}$ are assumed to be sufficiently large, so that $V_{C l}, V_{C 2}$, and $V_{o}$ are constant over one switching period. All the power semiconductor devices, i.e. $S W, D_{1}, D_{2}$, and $D_{3}$, are assumed to be an ideal switch.

In Continuous Conduction Mode (CCM), where the magnetizing current, $i_{L m}$, flows continuously and remains above zero throughout a switching period, the converter operation can be divided into three modes as follows.

Mode $1\left(\mathbf{t}_{\mathbf{0}}-\mathbf{t}_{\mathbf{1}}\right)$ : The equivalent circuit is shown in Fig. 3(b). $S W$ is turned on, $D_{2}$ is turned on, and $D_{1}$ and $D_{3}$ are turned off. The primary winding is supplied by $V_{i n}$, causing $i_{L m}$ to increase linearly and energy being stored in $L_{m}$. Since $D_{3}$ is turned off, both primary and secondary currents, $i_{1}$ and $i_{2}$, are zero. Meanwhile, $C_{1}$ is discharged by $C_{2}$ via $D_{2}$ and $S W$. At the output, $C_{3}$ is discharged by $R$, providing the load current, $I_{o}$.

From the equivalent circuit in Fig. 3(b), the following current relationships can be written:

$$
\begin{gathered}
i_{\text {in }}=i_{L m}, \\
i_{2}=0, \\
i_{D 1}=0, \\
i_{S W}=i_{\text {in }}+i_{D 2},
\end{gathered}
$$

where $i_{i n}$ is the input current, $i_{S W}$ is the switch current, $i_{D I}$ is a charging current from $L_{m}$ to $C_{1}$, and $i_{D 2}$ is a discharging current from $C_{1}$ to $C_{2}$. This mode is ended at time $t_{1}$ when $S W$ is turned off.

Mode $2\left(\mathbf{t}_{\mathbf{1}}-\mathbf{t}_{\mathbf{2}}\right)$ : The equivalent circuit is shown in Fig. 3(c). $S W$ is turned off, $D_{1}$ and $D_{3}$ are turned on, and $D_{2}$ is turned off. The primary voltage, $v_{l}$, is equal to $V_{\text {in }}-V_{C l}$,

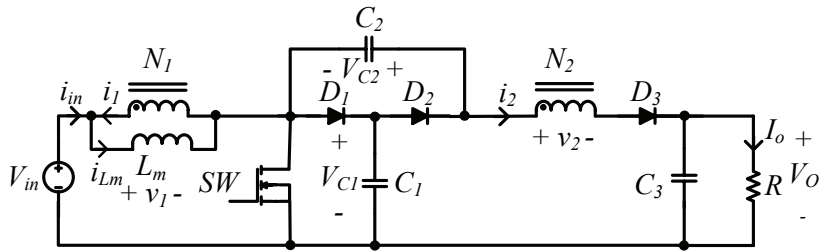

(a)

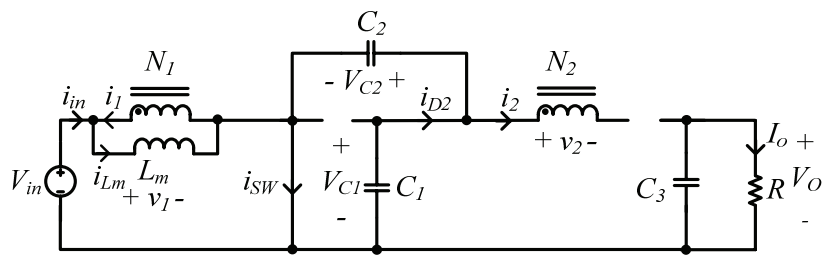

(b)

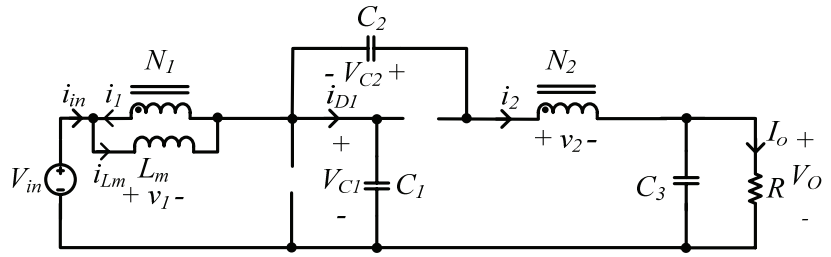

(c)

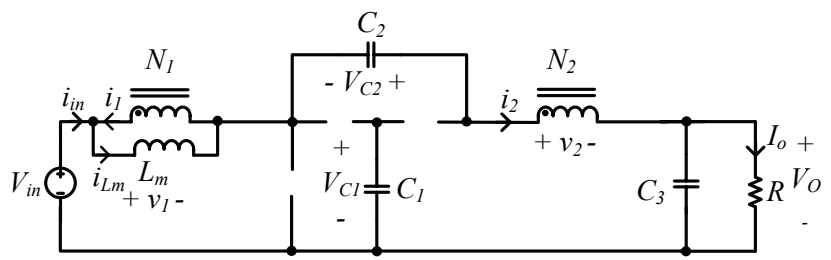

(d)

Fig. 3. Proposed converter: (a) circuit diagram; (b) operational mode 1; (b) operational mode 2, and (d) operational mode 3

which is negative because $V_{C l}$ is greater than $V_{i n}$. Alternatively, considering the outer loop of Fig. 3(c), $v_{l}$ can also be expressed as

$$
v_{1}=V_{i n}+V_{C 2}-v_{2}-V_{o}=V_{i n}+V_{C 2}-n v_{1}-V_{o} .
$$

That is,

$$
v_{1}=\frac{V_{i n}+V_{C 2}-V_{o}}{(1+n)}=V_{i n}-V_{C 1} .
$$

Since $v_{l}$ is negative, $i_{L m}$ decreases linearly and the energy stored in $L_{m}$ is released to charge $C_{l}$ via $D_{l}$ and to charge $C_{3}$ via $D_{3}$. The voltage across $S W$ is clamped to $V_{C l}$. Meanwhile, $C_{2}$ is discharged by the current $i_{2}$. Notice that $C_{2}$ is connected in series with the input voltage source and the primary and secondary windings of the coupled inductor; the sum of the voltages across these components is equal to the output voltage.

From the equivalent circuit in Fig. 2(c), the following current relationships can be written: 


$$
\begin{gathered}
i_{\text {in }}=i_{L m}-i_{1}=i_{L m}-n i_{2}, \\
i_{D 1}=i_{\text {in }}-i_{2}=i_{L m}-(n+1) i_{2}, \\
i_{S W}=0 .
\end{gathered}
$$

This mode is ended at time $t_{2}$ when $i_{D I}=0$ (i.e. $C_{I}$ is fully charged).

Mode $3\left(\mathbf{t}_{2}-\mathbf{t}_{3}\right)$ : The equivalent circuit is shown in Fig. 3(d). $S W$ is turned off, $D_{1}$ and $D_{2}$ are turned off, and $D_{3}$ is turned on. The primary voltage, $v_{l}$, is the same as in mode 2 given by (8). Since $v_{l}$ remains negative, $i_{L m}$ continues to decrease and the energy stored in $L_{m}$ is released to charge $C_{3}$ via $D_{3}$. Meanwhile, $C_{1}$ is floating. $C_{2}$ continues to be discharged by the current $i_{2}$. Still, in this mode, $C_{2}$ is connected in series with the input voltage source and the primary and secondary windings of the coupled inductor; the sum of the voltages across these components is equal to the output voltage.

From the equivalent circuit in Fig. 3(d), the following current relationships can be written:

$$
\begin{gathered}
i_{i n}=i_{2}, \\
i_{2}=\frac{i_{L m}}{n+1}, \\
i_{D 1}=0, \\
i_{S W}=0 .
\end{gathered}
$$

This mode is ended at time $t_{3}$ when $S W$ is turned on, thereby repeating mode 1 again.

Based on (3) to (15), key waveforms of the proposed converter can be drawn as shown in Fig. 4. The time duration when $S W$ is turned on (i.e. mode 1) is $D T$, where $D$ is the duty cycle of $S W$ and $T$ a switching period. The time duration when SW is turned off (i.e. mode 2 and 3 ) is (1-D)T. The current $i_{D l}$, which is a charging current from $L_{m}$ to $C_{l}$, has a triangle shape similar to that in the clampmode boost converter [12]. The current $i_{D 2}$, which is a discharging current from $C_{1}$ to $C_{2}$, is approximated by a pulse current with an amplitude $I_{p}$. The bottom two waveforms in Fig. 4 depict the currents $i_{C 1}$ and $i_{C 2}$. $C_{1}$ is discharged by $i_{D 2}$ during the time duration $D T$ and charged by $i_{D 1}$ during the time duration $(1-D) T . C_{2}$ is charged by $i_{D 2}$ during $D T$ and discharged by $i_{2}$ during $(1-D) T$.

In steady state, the voltage $v_{l}$ in Fig. 4 averaged over one switching period must be zero, that is

$$
\frac{V_{i n} D T+\left(V_{i n}-V_{C 1}\right)(1-D) T}{T}=0 \text {. }
$$

The above equation yields

$$
V_{C 1}=V_{C 2}=\frac{V_{\text {in }}}{1-D}
$$

Note that $V_{C l}=V_{C 2}$ because $C_{1}$ and $C_{2}$ are connected in

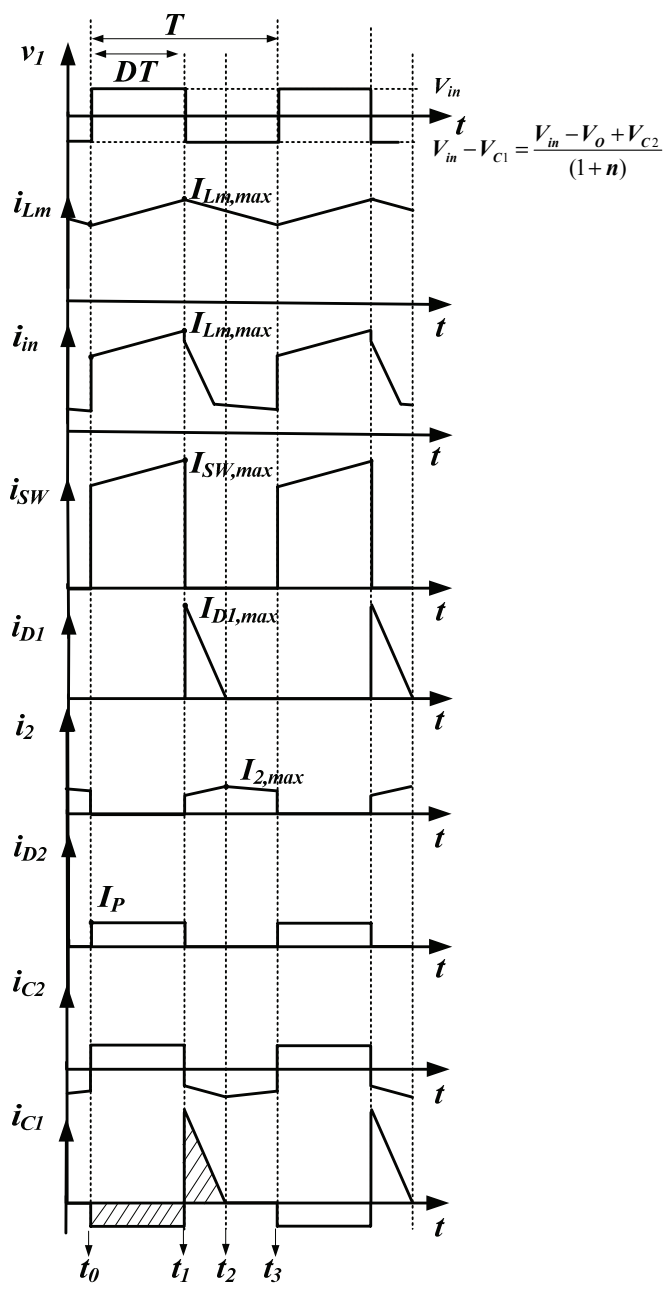

Fig. 4. Key waveforms of the proposed converter

parallel during the operational mode 1 (Fig. 3(b)) and, in this analysis, the capacitor voltages are assumed to be constant over one switching period. It can be seen from (17) that the switch clamp voltage, $V_{C l}$, of the proposed converter is identical to that in (2). This indicates that the proposed converter preserves the voltage clamping property of the clamp-mode coupled-inductor boost converter, despite the addition of $C_{2}-D_{2}$.

According to (8), Eq. (16) can be rewritten as

$$
\frac{V_{i n} D T+\frac{\left(V_{i n}-V_{o}+V_{C 2}\right)}{1+n}(1-D) T}{T}=0 .
$$

Solving (18), the voltage gain of the proposed converter is obtained as

$$
\frac{V_{o}}{V_{i n}}=\frac{2+n D}{1-D}
$$

Comparing (19) to (1), it is evident that the voltage gain of the proposed converter is greater than the clamp-mode 
coupled-inductor boost converter. For example, if $n=5$ and $D=0.5$, the voltage gain of the proposed converter would be nine, whereas the clamp-mode boost converter would be seven. Fig. 5 plots the voltage gain in (19) as a function of the duty cycle, with the different coupled inductor's turn ratios. From the graph, it can be seen that, for a given duty cycle, the gain becomes larger as $n$ is increased. Hence, by appropriately selecting $n$, the proposed converter can provide the high voltage gain, without operating at the extreme duty cycle.

By inspecting each operational mode in Fig. 3, the blocking voltages of power semiconductor devices in the proposed converter circuit can be determined as given below

$$
\begin{gathered}
V_{S W, \text { max }}=V_{C 1}=V_{o}+n V_{i n}-(n+1) V_{C 1}, \\
V_{\mathrm{D} 1, \max }=V_{C 2}, \\
V_{\mathrm{D} 2, \max }=V_{C 2}, \\
V_{D 3, \max }=V_{o}+n V_{\text {in }}-V_{C 1},
\end{gathered}
$$

where $V_{S W, \max }, V_{D 1, \max }, V_{D 2, \max }$, and $V_{D 3, \max }$ are the blocking voltages of $S W, D_{1}, D_{2}$, and $D_{3}$ respectively. These equations provide a basis for determining voltage ratings of the power semiconductor devices used in the proposed converter.

\section{Waveform Approximation and Analysis}

To derive the expressions for $I_{L m, \max }, I_{s w, \max }, I_{D 1, \max }$, $I_{2, \max }$, and $I_{p}$ in Fig. 4 , the proposed converter is assumed to be operating with the time interval in mode 2 relatively short compared with the time interval in mode 1 and 3 . As a result, the operating mode 2 can be omitted from the converter operation and the waveforms in Fig. 4 can be approximated as shown in Fig. 6, where the time interval $t_{1}-t_{2}$ becomes zero and the operating mode 3 takes up the entire $(1-D) T$ interval. It should be noted that as the time interval $t_{1}-t_{2}$ approaches zero, $i_{D 1}$ becomes an impulse current which is represented by the vertical arrow in Fig. 6 . In figure, $I_{L m}, I_{L m, \max }$, and $I_{L m, \min }$ are the average, maximum, and minimum magnetizing currents respectively. $I_{s w, \max }$ is the maximum switch current. $I_{2}, I_{2, \max }$, and $I_{2, \min }$ are the average, maximum, and minimum secondary currents respectively. $I_{2, \text { nom }}$, which is an average value between $I_{2, \max }$ and $I_{2, \min }$, is referred to as the nominal secondary current. The expressions for these current quantities are derived as follows.

Beginning with the secondary current, since $i_{2}$ is feeding $C_{3}$ in parallel with $R$, the average secondary current, $I_{2}$, is equal to the output current, $I_{o}$ :

$$
I_{2}=I_{o}
$$

Given $I_{2}$ in (24), $I_{2, \text { nom }}$ can be determined from

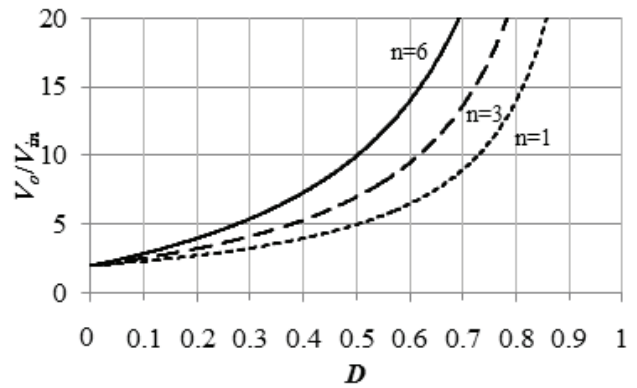

Fig. 5. Voltage gain vs duty cycle

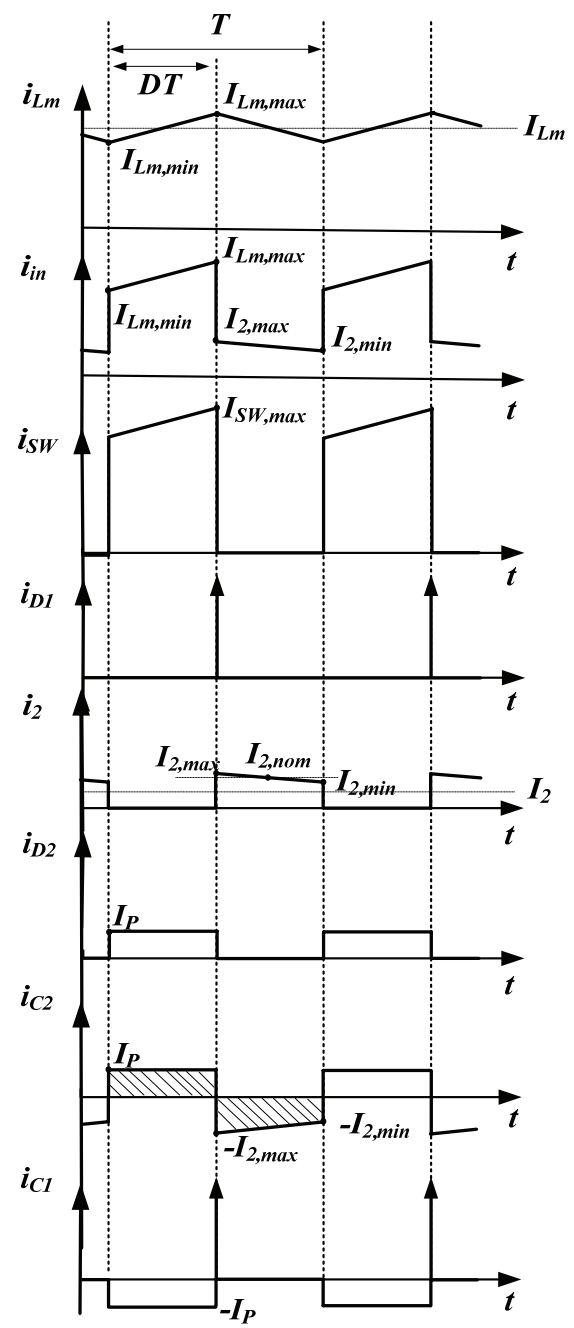

Fig. 6. Approximated waveforms of the proposed converter

$$
I_{2, \text { nom }}(1-D) T=I_{2} T \text {. }
$$

The above equation gives

$$
I_{2, \text { nom }}=\frac{I_{O}}{1-D}
$$

The average input current, $I_{i n}$, in Fig. 6 can be expressed as 


$$
I_{\text {in }}=\frac{I_{L m} D T+I_{2, n o m}(1-D) T}{T}=I_{L m} D+I_{o} .
$$

For the lossless converter, the input power is equal to the output power, i.e.

$$
I_{\text {in }}=\left(\frac{V_{o}}{V_{\text {in }}}\right) I_{o}
$$

Substituting $V_{o} / V_{i n}$ in (19) and $I_{i n}$ in (27) into (28), $I_{L m}$ is obtained as

$$
I_{L m}=\left(\frac{2+n D}{1-D}-1\right) \frac{I_{o}}{D} .
$$

Given $I_{L m}$ in (29), the maximum and minimum magnetizing currents can be found as

$$
\begin{aligned}
& I_{L m, \max }=I_{L m}+\frac{\Delta i_{L m}}{2}=I_{L m}+\frac{V_{i n} D T}{2 L_{m}} \\
& I_{L m, \min }=I_{L m}-\frac{\Delta i_{L m}}{2}=I_{L m}-\frac{V_{i n} D T}{2 L_{m}} .
\end{aligned}
$$

Since $i_{2}=i_{L m} /(n+1)$ during the time duration $(1-D) T$, the maximum and minimum secondary current can be expressed in terms of $I_{L m, \max }$ and $I_{L m, \min }$ as

$$
\begin{aligned}
& I_{2, \max }=\frac{I_{L m, \max }}{(n+1)}, \\
& I_{2, \min }=\frac{I_{L m, \min }}{(n+1)} .
\end{aligned}
$$

In steady state, the positive and negative areas under the $i_{C 2}$ waveform in Fig. 6 must be equal, i.e.

$$
I_{p} D T=I_{2, \text { nom }}(1-D) T .
$$

Substituting $I_{2, \text { nom }}$ in (26) into (34), $I_{p}$ is obtained as

$$
I_{p}=\frac{I_{o}}{D}
$$

The maximum switch current, $I_{S W, \max }$, in Fig. 6 is given by

$$
I_{S W, \max }=I_{L m, \max }+I_{p} .
$$

Finally, in steady state, the positive and negative areas under the $i_{C l}$ waveform in Fig. 4 must be equal, i.e.

$$
I_{p} D T=\frac{1}{2} t_{12} I_{D 1, \max }
$$

The above equation yields

$$
I_{D 1, \max }=\frac{2 I_{p} D T}{t_{12}}
$$

where $t_{12}$ is the time interval $t_{1}-t_{2}$. If $t_{12}$ is known, $I_{D 1, \max }$ can be calculated. It should be emphasized that $I_{L m, \max }$ in (30), $I_{2, \text { max }}$ in (32), $I_{p}$ in (35), $I_{S W, \text { max }}$ in (36), and $I_{D I, \text { max }}$ in (38) provide a basis for determining current ratings of the power semiconductor devices used in the proposed converter. The validity of these derived current expressions is verified in the next section.

\section{Experimental Results}

\subsection{Step-up Gain of 10}

The proposed converter in Fig. 3 is prototyped as shown in Fig. 7. The input voltage, $V_{i n}$, is $12 \mathrm{~V}$, the output voltage, $V_{o}$, is $120 \mathrm{~V}$, and the switching frequency is $100 \mathrm{kHz}$ (the switching period $T=10 \mu \mathrm{s}$ ). The load current, $I_{o}$, can vary from $0.3 \mathrm{~A}$ to $0.9 \mathrm{~A}$, which is equivalent to the output power between $36 \mathrm{~W}$ and $108 \mathrm{~W}$. Table 1 lists the devices and components used in the prototype converter.

Fig. 8 shows the output voltage and current waveforms measured from the prototype for the three loading conditions, i.e. $I_{o}=0.3 \mathrm{~A}, I_{o}=0.6 \mathrm{~A}$, and $I_{o}=0.9 \mathrm{~A}$. In each case, the input voltage is fixed at $12 \mathrm{~V}$ and the duty cycle of the MOSFET gate drive signal is adjusted to give the constant

Table 1. Devices and components used in the prototype converter

\begin{tabular}{c|c}
\hline Component/Devices & Description \\
\hline & $L_{m}=60 \mu \mathrm{H}, n=6$ \\
Coupled inductor & $\begin{array}{c}\text { ETD59 ferrite core, gap }=0.3 \mathrm{~mm} N_{l}=11 \text { turns, } \\
\text { copper strip (width: } 22 \mathrm{~mm})\end{array}$ \\
& $N_{2}=66$ turns, 4xAWG20 copper wire \\
\hline & Electrolytic capacitor \\
Capacitors & $C_{l}=180 \mu \mathrm{F} \quad(100 \mathrm{~V})$ \\
& $C_{2}=180 \mu \mathrm{F} \quad(100 \mathrm{~V})$ \\
& $C_{3}=180 \mu \mathrm{F} \quad(100 \mathrm{~V})$ \\
\hline$D_{1}, D_{2}$, and $D_{3}$ & MUR840 $(400 \mathrm{~V}, 8 \mathrm{~A})$ ultrafast diode \\
\hline$S W$ & IRF3710 $(100 \mathrm{~V}, 57 \mathrm{~A})$ power MOSFET \\
\hline
\end{tabular}

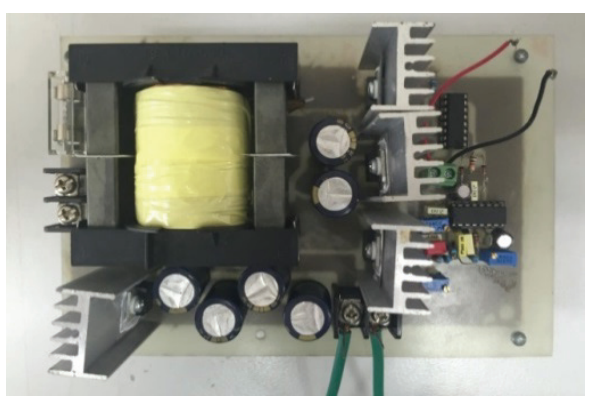

Fig. 7. Photo of the prototype converter 
output voltage of $120 \mathrm{~V}$. The duty cycles used to achieve this tenfold voltage gain are recorded and shown in Table 2 . The duty cycle is 0.5 when $I_{o}=0.3 \mathrm{~A}$, is 0.53 when $I_{o}=$ $0.6 \mathrm{~A}$, and is 0.56 when $I_{o}=0.9 \mathrm{~A}$. The duty cycle increases

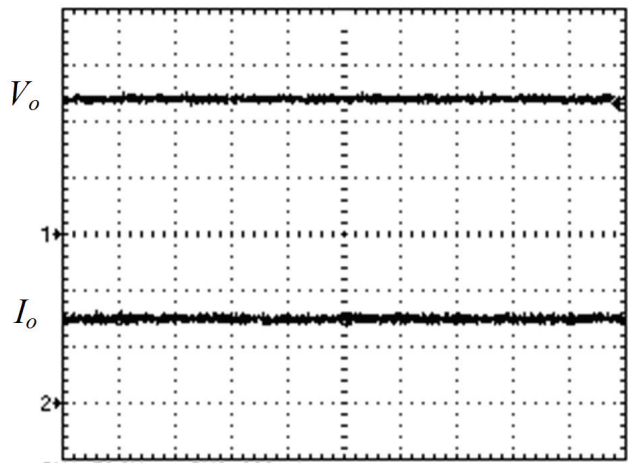

(a) $\mathrm{x}$-scale: $2.5 \mu \mathrm{s} / \mathrm{div}$

Top trace $V_{o}: 50 \mathrm{~V} / \mathrm{div}$, Bottom trace $I_{o}: 0.2 \mathrm{~A} / \mathrm{div}$

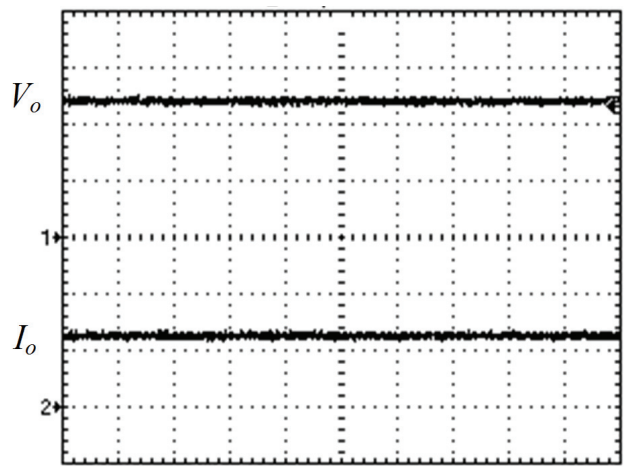

(b) $\mathrm{x}$-scale: $2.5 \mu \mathrm{s} / \mathrm{div}$

Top trace $V_{o}: 50 \mathrm{~V} / \mathrm{div}$, Bottom trace $I_{o}: 0.5 \mathrm{~A} / \mathrm{div}$

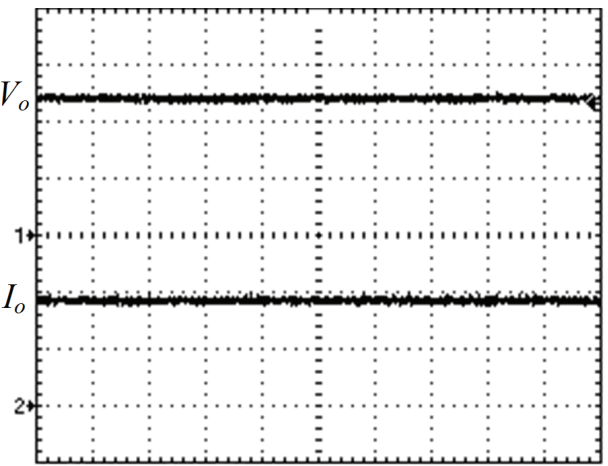

(c) $\mathrm{x}$-scale: $2.5 \mu \mathrm{s} / \mathrm{div}$

Top trace $V_{o}: 50 \mathrm{~V} / \mathrm{div}$, Bottom trace $I_{o}: 0.5 \mathrm{~A} / \mathrm{div}$

Fig. 8. Output voltage and current waveforms at: (a) $I_{o}=$ $0.3 \mathrm{~A}$, (b) $I_{o}=0.6 \mathrm{~A}$, and (c) $I_{o}=0.9 \mathrm{~A}$

Table 2. Duty cycle and efficiency measurement for stepup gain of 10

\begin{tabular}{c|c|c|c|c|c}
\hline $\mathrm{I}_{\mathrm{o}}$ & $\mathrm{V}_{\mathrm{o}}$ & $\mathrm{I}_{\text {in }}$ & $\mathrm{V}_{\text {in }}$ & Efficiency & $\mathrm{D}$ \\
\hline 0.30 & 120.22 & 3.24 & 12 & $92.8 \%$ & 0.50 \\
\hline 0.62 & 120.22 & 7.28 & 12 & $85.3 \%$ & 0.53 \\
\hline 0.92 & 120.22 & 11.55 & 12 & $79.8 \%$ & 0.56 \\
\hline
\end{tabular}

at high load currents to compensate for the increased voltage drop caused by circuit non-idealities, such as the leakage inductance and winding resistance of the coupled inductor, the MOSFET's on-state resistance $\left(R_{d s, o n}\right)$, the forward voltage drop of the diodes, etc. By substituting $V_{\text {in }}$ $=12 \mathrm{~V}, V_{o}=120 \mathrm{~V}$, and $n=6$ into (19), the theoretical duty cycle is calculated as $D=0.5$. The actual duty cycles shown in Table 2 closely agree with the theoretical value.

Also shown in Table 2 is the efficiency measurement result. The converter efficiency, defined as a product of the average output voltage $\left(V_{o}\right)$ and current $\left(I_{o}\right)$ divided by a product of the average input voltage $\left(V_{i n}\right)$ and current $\left(I_{\text {in }}\right)$, has the maximum value of $92.8 \%$ at $I_{o}=0.3 \mathrm{~A}$. The efficiency is reduced as the load current is further increased.

The decrease in efficiency at high load currents is caused by the increase in conduction losses of $S W, D_{1}, D_{2}$ and $D_{3}$.

Fig. 9 shows the key current waveforms measured from the prototype, when $I_{o}=0.9 \mathrm{~A}$. It can be seen that the measured current waveforms are similar to the theoretical waveforms in Fig. 4. The important current quantities, which include $I_{L m, \max }, I_{2, \max }, I_{p}$, and $I_{S W, \max }$ are measured and compared with the calculation based on (30), (32), (35), and (36) respectively. The comparison results are given in Table 3 . It is seen that the calculated currents closely

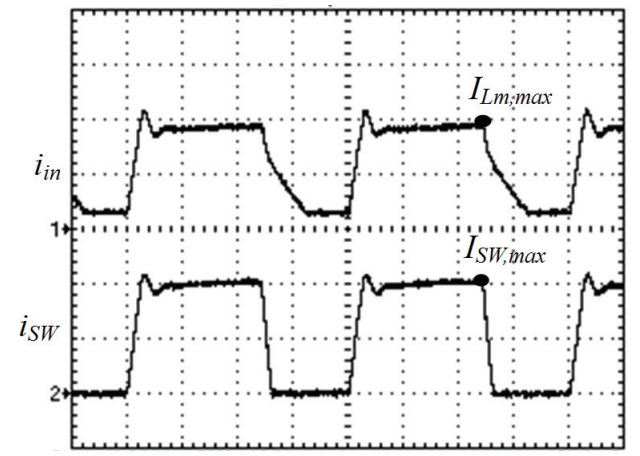

(a) $\mathrm{x}$-scale: $2.5 \mu \mathrm{s} / \mathrm{div}$

Top trace $i_{\text {in }}: 10 \mathrm{~A} / \mathrm{div}$, Bottom trace $i_{S W}: 10 \mathrm{~A} / \mathrm{div}$

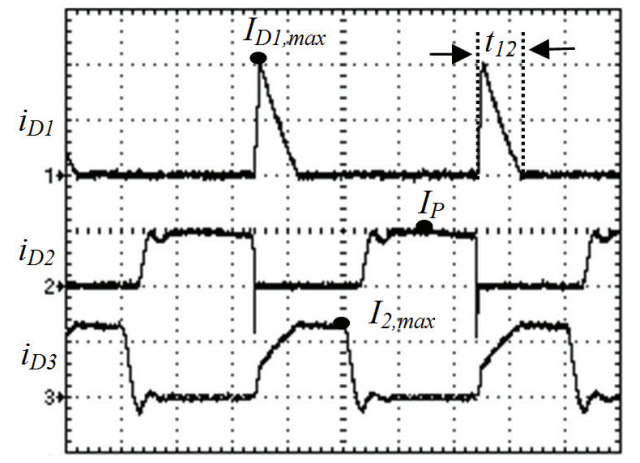

(b) $\mathrm{x}$-scale: $2.5 \mu \mathrm{s} / \mathrm{div}$

Top trace $i_{D 1}: 5 \mathrm{~A} / \mathrm{div}$, Middle trace $i_{D 2}: 2 \mathrm{~A} / \mathrm{div}$ Bottom trace $i_{D 3}: 2 \mathrm{~A} / \mathrm{div}$

Fig. 9. Key current waveforms at $I_{\mathrm{o}}=0.9 \mathrm{~A}$ for step-up gain of 10 
Table 3. Comparison between calculated and measured currents

\begin{tabular}{c|c|c|c|c|c|c}
\hline \multirow{2}{*}{ Quantity } & \multicolumn{2}{|c|}{$I_{o}=0.3 \mathrm{~A}$} & \multicolumn{2}{c|}{$I_{o}=0.6 \mathrm{~A}$} & \multicolumn{2}{c}{$I_{o}=0.9 \mathrm{~A}$} \\
\cline { 2 - 7 } & Cal. & Mea. & Cal. & Mea. & Cal. & Mea. \\
\hline$I_{L m, \max }$ & 5.9 & 5.8 & 11.9 & 11.8 & 18.5 & 18 \\
\hline$I_{2, \max }$ & 0.8 & 0.7 & 1.7 & 1.6 & 2.6 & 2.6 \\
\hline$I_{P}$ & 0.6 & 0.6 & 1.1 & 1.2 & 1.6 & 2.0 \\
\hline$I_{s w, \max }$ & 6.5 & 6 & 13 & 13 & 20.1 & 20 \\
\hline
\end{tabular}

Table 4. Capacitor voltage measurement

\begin{tabular}{c|c|c|c|c|c|c}
\hline \multirow{2}{*}{ Quantity } & \multicolumn{2}{|c|}{$I_{o}=0.3 \mathrm{~A}$} & \multicolumn{2}{c|}{$I_{o}=0.6 \mathrm{~A}$} & \multicolumn{2}{c}{$I_{o}=0.9 \mathrm{~A}$} \\
\cline { 2 - 7 } & Cal. & Mea. & Cal. & Mea. & Cal. & Mea. \\
\hline$V_{C 1}$ & 24.2 & 24.8 & 25.4 & 26.7 & 27.0 & 28.8 \\
\hline$V_{C 2}$ & 24.2 & 23.6 & 25.4 & 25 & 27.0 & 26.8 \\
\hline
\end{tabular}

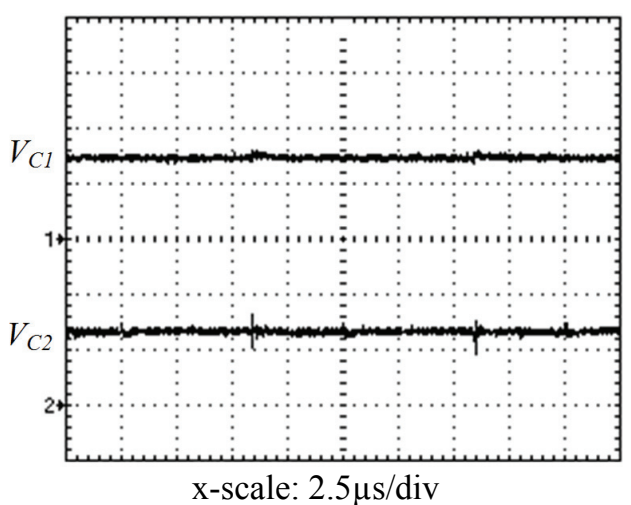

Top trace $V_{C l}: 20 \mathrm{~V} /$ div, Bottom trace $V_{C 2}: 20 \mathrm{~V} / \mathrm{div}$

Fig. 10. Voltage across capacitor $C_{1}$ and $C_{2}$ at $I_{\mathrm{o}}=0.9 \mathrm{~A}$

agree with the measured currents for all loading conditions. Furthermore, from the $i_{D 1}$ waveform in Fig. 9(b), the time interval $t_{1}-t_{2}$ is found to be $t_{12}=2 \mu \mathrm{s}$. Given this time interval, $I_{D I \max }$ can be calculated from (38):

$$
I_{D 1, \max }=\frac{2 I_{p} D T}{t_{12}}=\frac{2 \times 1.6 \times 0.56 \times 10 \times 10^{-6}}{2 \times 10^{-6}}=9 \mathrm{~A}
$$

The calculated $I_{D I \max }$ is consistent with the actual value in Fig. 9(b), where $I_{D I, \max } \approx 10 \mathrm{~A}$. The consistency between the calculated and measured results in all the above cases confirms the validity of the current expressions derived via waveform approximation in Section 4.

Fig. 10 shows the waveforms of $V_{C I}$ and $V_{C 2}$ measured from the prototype, when $I_{o}=0.9 \mathrm{~A}$. Both capacitor voltages are relatively constant, with the amplitude $V_{C l}=28.8 \mathrm{~V}$ and $V_{C 2}=26.8 \mathrm{~V}$. The capacitor voltage measurement for all loading conditions is summarized in Table 4. As seen in the table, the measured capacitor voltages conform with the calculation by (17). Note that $V_{C l}$ is slightly higher than $V_{C 2}$ because, when $C_{1}$ is discharged to $C_{2}$ in mode 1 (Fig. $3 \mathrm{~b}$ ), there are some voltage drops across $D_{2}$ and $S W$.

Fig. 11 shows the voltage waveforms across the power semiconductor devices measured from the prototype, when $I_{o}=0.9 \mathrm{~A}$. As seen in the $v_{s w}$ waveforms, there is an initial

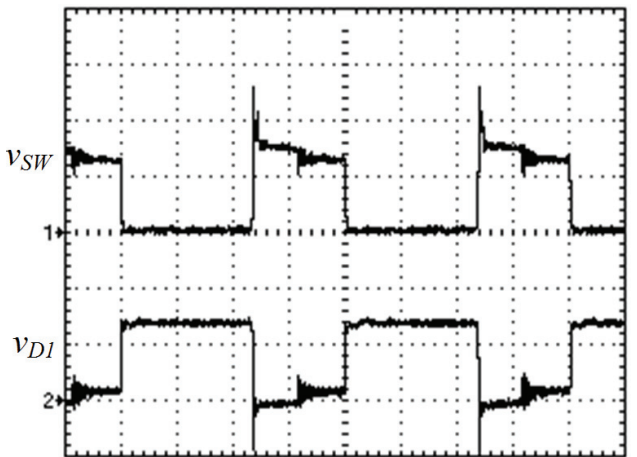

(a) $\mathrm{x}$-scale: $2.5 \mu \mathrm{s} / \mathrm{div}$

Top trace $v_{S W}: 20 \mathrm{~V} /$ div, Bottom trace $v_{D I}: 20 \mathrm{~V} / \mathrm{div}$

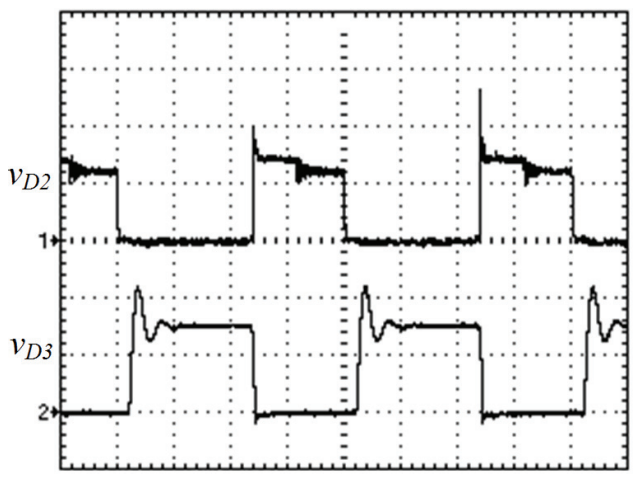

(b) $\mathrm{x}$-scale: $2.5 \mu \mathrm{s} / \mathrm{div}$

Top trace $v_{D 2}: 20 \mathrm{~V} / \mathrm{div}$, Bottom trace $v_{D 3}: 100 \mathrm{~V} / \mathrm{div}$

Fig. 11. Voltage waveforms across power semiconductor devices at $I_{o}=0.9 \mathrm{~A}$

voltage spike when $S W$ is turned off caused by the leakage inductance of the coupled inductor. After the voltage spike has died out, the switch voltage is clamped to $V_{C l}=28.8 \mathrm{~V}$, corresponding with (20). Subsequently, as the converter operation enters mode $3, S W$ is no longer clamped by $C_{l}$ and the switch voltage is reduced to about $26 \mathrm{~V}$ imposed by the input voltage and primary voltage of the couple inductor (see Fig. 3(d)). Similarly, the initial voltage spike and the subsequent voltage transition are also observed in the $v_{D 1}$ and $v_{D 2}$ waveforms. As seen in the bottom trace of Fig. 11, $v_{D 3}$ exhibits a high frequency ringing, when $D_{3}$ is turned off. This is caused by the resonance between a leakage inductance of the coupled inductor and a parasitic capacitance of $D_{3}$. It should be noted that in the experimental prototype, there is an $R C$ snubber $(R=150 \Omega$ and $C=3 \mathrm{nF}$ ) connected across $D_{3}$; therefore the effect of the resonance has been somewhat attenuated. Without the snubber, the ringing would be more pronounced. After the ringing has subsided, $v_{D 3}$ in Fig. 11 is subjected to the blocking voltage of $150 \mathrm{~V}$, which is lower than $V_{D 3, \max }=$ $165 \mathrm{~V}$ calculated by (23).

Finally, a comparison is made between the proposed converter and the Integrated Boost Flyback Converter (IBFC) $[5,15]$ with regard to the stress of a power switch and converter efficiency. The IBFC prototype used in this 
study has the same circuit specifications and coupled inductor parameters as the proposed converter. Fig. 12 shows the voltage and current waveforms of the MOSFET switch measured from the two prototype circuits. It can be seen that the peak switch voltages and currents in both converters are similar; hence the devices are essentially subjected to the same level of stresses. Despite the equal voltage and current stresses on the power switches, the voltage gain of the proposed converter (19) nonetheless is higher than the IBFC, whose gain is identical to the clampmode boost converter in (1). Thus, as evident in Fig. 12, the MOSFET switch of the IBFC has to operate with the greater duty cycle (the longer conduction time) than the

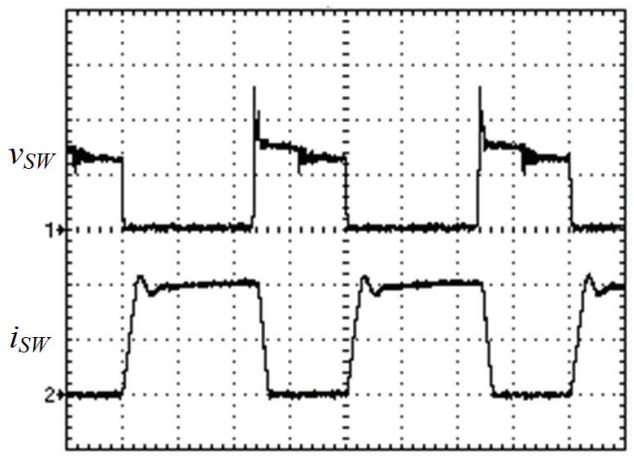

(a) $\mathrm{x}$-scale: $2.5 \mu \mathrm{s} / \mathrm{div}$

Top trace $v_{S W}: 20 \mathrm{~V} /$ div, Bottom trace $I_{S W}: 10 \mathrm{~A} / \mathrm{div}$

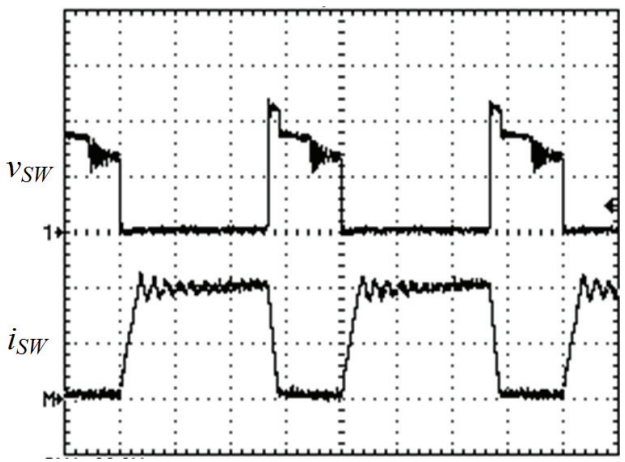

(b) $\mathrm{x}$-scale: $2.5 \mu \mathrm{s} / \mathrm{div}$

Top trace $v_{S W}: 20 \mathrm{~V} / \mathrm{div}$, Bottom trace $I_{S W}: 10 \mathrm{~A} / \mathrm{div}$

Fig. 12. Voltage and current waveforms of the MOSFET switch at $I_{o}=0.9 \mathrm{~A}$ : (a) proposed converter (b) IBFC

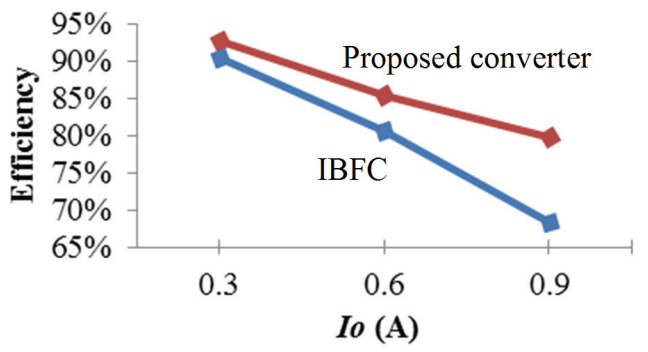

Fig. 13. Efficiency comparison between the proposed converter and IBFC proposed converter in order to achieve the tenfold step-up gain. The greater duty cycle causes the average switch current of the IBFC to be higher than the proposed converter. The higher average currents yield the greater conduction losses, which are responsible for the efficiency of the IBFC being lower than the proposed converter for the entire load currents, as shown in Fig. 13.

\subsection{Step-up Gain of 5}

The prototype converter in Fig. 7 is also experimented at a step-up gain of 5 with $V_{\text {in }}=24 \mathrm{~V}, V_{o}=120 \mathrm{~V}$ and $I_{o}=0.3 \mathrm{~A}$ to $1.8 \mathrm{~A}$ (i.e. $P_{o}=36 \mathrm{~W}$ to $216 \mathrm{~W}$ ). The circuit parameters and components are the same as those listed in Table 1. The purpose of this experiment is to demonstrate that the

Table 5. Duty cycle and efficiency measurement for stepup gain of 5

\begin{tabular}{c|c|c|c|c|c}
\hline$I_{\mathrm{O}}$ & $V_{\mathrm{O}}$ & $I_{\text {in }}$ & $V_{\text {in }}$ & Efficiency & $D$ \\
\hline 0.32 & 120.22 & 1.73 & 24 & $92.7 \%$ & 0.25 \\
\hline 0.62 & 120.22 & 3.53 & 24 & $88.0 \%$ & 0.27 \\
\hline 0.92 & 120.22 & 5.24 & 24 & $87.9 \%$ & 0.28 \\
\hline 1.24 & 120.22 & 7.25 & 24 & $85.7 \%$ & 0.29 \\
\hline 1.54 & 120.22 & 9.21 & 24 & $83.8 \%$ & 0.30 \\
\hline 1.84 & 120.22 & 11.38 & 24 & $81.0 \%$ & 0.32 \\
\hline
\end{tabular}

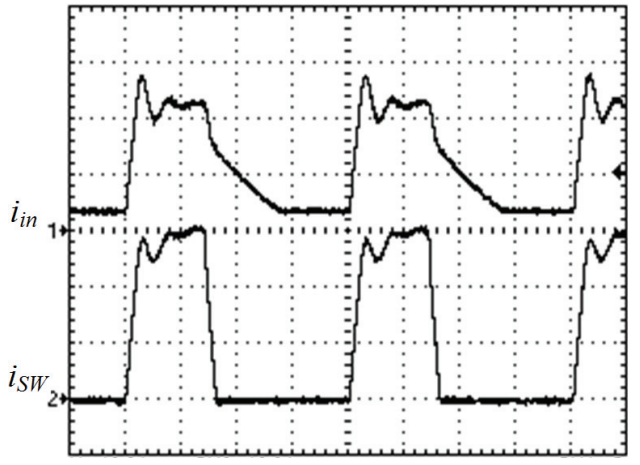

(a) $\mathrm{x}$-scale: $2.5 \mu \mathrm{s} / \mathrm{div}$

Top trace $i_{i n}: 10 \mathrm{~A} /$ div, Bottom trace $i_{S W}: 10 \mathrm{~A} /$ div

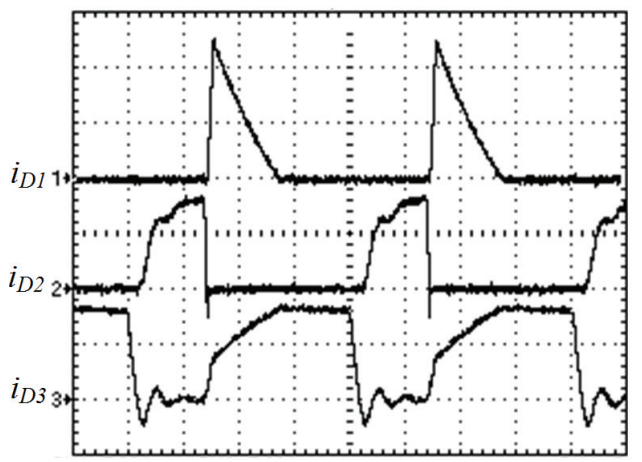

(b) $\mathrm{x}$-scale: $2.5 \mu \mathrm{s} / \mathrm{div}$

Top trace $i_{D 1}: 5 \mathrm{~A} / \mathrm{div}$, Middle trace $i_{D 2}: 5 \mathrm{~A} / \mathrm{div}$

Bottom trace $i_{D 3}: 2 \mathrm{~A} / \mathrm{div}$

Fig. 14. Key current waveforms at $I_{0}=1.8 \mathrm{~A}$ for step-up gain of 5 
proposed converter can work satisfactorily at a different step-up gain. The duty cycle and efficiency measurement are shown in Table 5. When the load current is increased from $I_{o}=0.3 \mathrm{~A}$ to $1.8 \mathrm{~A}$, the duty cycle required to maintain $V_{o}$ at $120 \mathrm{~V}$ has increased slightly from 0.25 to 0.32 , and the converter efficiency drops from $92.7 \%$ to $81 \%$. As explained before, the higher duty cycle is needed to compensate for the increased voltage drop in the circuit at higher load power. Meanwhile, the efficiency decreases at higher load power due to the increase in conduction losses.

Fig. 14. shows the key current waveforms measured at the maximum load power $\left(P_{o}=216 \mathrm{~W}\right)$. The waveforms generally resemble their counterparts in Fig. 9. The duty cycle of the MOSFET switch is evidently lowered for the step-up gain of 5 as can be seen by comparing the width of the $i_{s w}$ waveforms in Fig. 9 and Fig. 14.

\section{Conclusion}

This paper has proposed a novel clamp-mode coupled inductor boost converter with a high step-up voltage gain. It was developed from the original clamp-mode converter in Fig. 1(a) by incorporating an additional capacitor $\left(C_{2}\right)$ and diode $\left(D_{2}\right)$. During a turn-off period of the main switch, $C_{2}$ is discharged in series with the input voltage source and the primary and secondary windings of the coupled inductor. As a result, the voltages across these components are added together to produce the output voltage. Due to the contribution by $C_{2}$, the voltage gain of the proposed converter is higher than the clamp-mode boost converter. The operation of the proposed converter was described and analyzed, leading to the mathematical expressions for the voltage gain, switch clamp voltage, and various current quantities. The calculation by the derived expressions was found to be highly consistent with the measurement results from the prototype circuit, confirming the validity of the presented analysis. The experimental prototype converter was tested for step-up gain of 10 and 5. Both cases yield the similar value of maximum efficiency.

\section{References}

[1] Q. Zhao and F.C. Lee, "High-Efficiency, High StepUp DC-DC Converters," IEEE Trans. Power Electron, vol. 18, no. 1, pp. 65-73, Jan. 2003.

[2] B. Axelrod, Y. Berkovich, and A. Ionovici, "SwitchedCapacitor/Switched-inductor Structures for Getting Transformerless Hybrid DC- DC PWM Converters," IEEE Trans. Circuits and Systems, vol. 55, no. 2, pp. 687-696, Mar. 2008.

[3] R.J. Wai, W.H. Wang, and C.Y. Lin, "High-Performance Stand-Alone Photovoltaic Generation System," IEEE Trans. Ind. Electron, vol. 55, no. 1, pp. 272280, Jan. 2008.
[4] D. W. Hart, Power Electronics: Mcgraw Hill, 2011, p.211-220.

[5] K. C. Tseng and T. J. Liang, "Novel high-effciency step-up converter," IEE Proc.-Electr. Power Appl, vol. 151, no. 2, pp.182-190, Mar. 2004.

[6] L. Huber and M.M. Jovanovic, "A Design Approach for Server Power Supplies for Networking Applications," in Proceeding of APEC, pp. 1163-1169, Feb 2000.

[7] J. A. M. Saldana, E. E. C. Gutierrez, and J. L. Ranos, "Modelling of Switch-mode DC-DC Cascade Converters," IEEE Trans. Aerosp. Electron. Syst, vol. 38, no. 1, pp. 295-299, 2002

[8] F.L. Luo and H. Ye, "Positive Output Cascade Boost Converters," IEE Proc.-Electr. Power Appl, vol. 151, no.5, pp.590-606, 2004.

[9] J.A. M. Saldana, R. G. Quirino, J. L. Ramos, E.E. C. Gutie rrez, and M.G. O. Lopez, "Multiloop Controller Design for A Quadratic Boost Converter," IET Electr. Power Appl, vol.1, no. 3, pp. 362-367, 2007.

[10] M. G. Ortiz-Lopez, J. Leyva-Ramos, E. E. CarbajalGutierrez, and J.A. Morales-Salda, "Modelling and Analysis of Switch-mode Cascade Converters with A Single Active Switch," IET Power Electronics, vol. 1, no. 4, pp. 478-487, 2008.

[11] Q. Zhao, F. Tao, and F. C. Lee, "A Front-End DC/DC Converter for Network Server Applications," in Proceeding of PESC, pp. 109-113, Vancuver, Jun 2003.

[12] D. M. Van de Sype, K. De Gusseme, B. Renders, A. R. Van den Bossche, and J. A. Melkebeek, "A Single Switch Boost Converter With a High Conversion Ratio," in Proceeding of IEEE APEC, pp. 1581- 1587, Mar, 2005.

[13] B. Axelrod, Y. Berkovich, and A.Ioinovici, "Swiched Coupled-Inductor Cell for DC-DC Converters with Very Large Conversion Ratio," in Proceeding of IECON, pp. 2366-2371, Paris, Nov 2006.

[14] T. J. Liang and K. C. Tseng, "Analysis of integrated boost-flyback step-up converter," IEE Proc.-Electr. Power Appl., vol. 152, no. 2, March. 2005.

[15] K. Tattiwong and C. Bunlaksananusorn, "Design and Implementation of An Integrated Boost-Flyback Converter," in Proceeding of IECON, pp. 3491-3496, Yokohama, Nov 2015.

[16] G. Spiazzi, P. Mattavelli, J.R. Gazoli, R. Magalhaes, and G. Frattini, "Improved Integrated Boost-Flyback High Step-Up Converter," in Proceeding of ICIT, pp. 1169-1174, 2010.

[17] T. J. Liang, S. M. Chen, L. S. Yang, J. F. Chen, and A. Ioinovici, "A Single Switch Boost-Flyback DCDC Converter Integrated with Switched-Capacitor Cell," in Proceeding of ICPE \& ECCE, pp. 27822787, Jeju, Jun 2011.

[18] I. Laird, D. D. C. Lu, and V. G. Agelidis, "HighGain Switched-Coupled-Inductor Boost Converter," in Proceeding of PEDS, pp. 423-428, Taipei, Nov 
2009.

[19] D. A. Grant, Y. Darroman, and J. Suter, "Synthesis of Tapped-Inductor Switched-Mode Converters," IEEE Trans. On Power electronics, vol. 22, no. 5, pp. 1964-1969, 2007.

[20] N. Vazquez, L. Estrada, C. Hernandez, and E. Rodriguez, "The Tapped-Inductor Boost Converter," in Proceeding of IEEE International Symposium on Industrial Electronics, pp. 538-543, Jun 2007.

[21] M. N. Gitau, F. M. Mwaniki, and I. W. Hofsajer, "Analysis and Design of Single-Phase TappedCoupled-Inductor Boost DC-DC Converter," Journal of Power Electronics, vol. 13, no. 4, pp. 636-646, 2013.

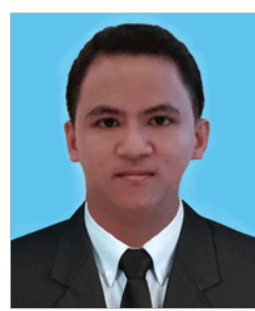

Kaweewat Tattiwong $\mathrm{He}$ received the B. Eng. degree in mechatronic engineering and M. Eng. degree in control engineering from King Mongkut's Institute of Technology Ladkrabang (KMITL), Thailand, in 2011 and 2013 respectively. His research interest is power electronics.

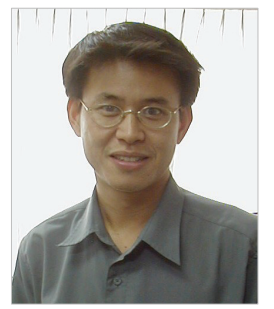

Chanin Bunlaksananusorn $\mathrm{He}$ received a Ph.D. degree in electrical engineering from The University of Edinburgh, UK, in 1997. He is currently an associate professor with the Faculty of Engineering, King Mongkut's Institute of Technology Ladkrabang (KMITL). His research interests are power electronics and energy conversion. 